Outros Tempos, vol. 14, n. 23, 2017 p. 240 -259. ISSN:1808-8031

DOI: http://dx.doi.org/10.18817/ot.v14i23.578

\title{
PATRIMÓNIO RURAL DO MOSTEIRO DE SÃO VICENTE DE FORA (LISBOA): séculos XII-XIII ${ }^{1}$
}

\author{
RURAL HERITAGE OF THE MONASTERY OF SÃO VICENTE DE FORA \\ (LISBOA): 12th-13th centuries
}
PATRIMONIO RURAL DEL MONASTERIO DE SAN VICENTE DE FORA (LISBOA): siglos XII-XIII

\author{
CARLOS GUARDADO DA SILVA \\ Professor Auxiliar com Agregação (Centro de Estudos Clássicos), \\ Faculdade de Letras, Universidade de Lisboa. \\ Lisboa, Portugal \\ carlosguardado@campus.ul.pt
}

\begin{abstract}
Resumo: O presente estudo, de natureza qualitativa e suportado em pesquisa documental, analisa o sistema de organização económica e a gestão do aro rural, nomeadamente a evolução das relações que se estabeleceram entre o Mosteiro de São Vicente de Fora e os particulares, assim como a diversificação e a expansão do seu património rural, mais intensas junto da cidade de Lisboa. Parte da conquista de Lisboa e da fundação do Mosteiro, em meados do século XII, seguindo-se uma análise do processo de formação e estruturação do património monástico, bem como das formas e estratégias de aquisição patrimonial, terminando com a composição da propriedade rural. Depois são apresentados os resultados, predominando na paisagem rural, por ordem decrescente, as herdades de "pão", as vinhas e os olivais, a par de outro tipo de propriedades rurais, assim como dos meios de transformação: moinhos e azenhas, lagares de vinho e azeite e fornos. Conclui que o Mosteiro adquirira e possuía um património concentrado na região de Lisboa, apesar da sua influência se estender a nível nacional, dados os direitos e os privilégios que possuía no reino.
\end{abstract}

Palavras-chave: História Medieval. Mosteiro de São Vicente de Fora. Património Rural. Propriedade rural. Paisagem rural. Portugal. Séculos XII-XIII.

\begin{abstract}
This present study, of qualitative nature and based on documentary research, analyzes the economical organization system and the management of rural suburbs, namely the evolution of relationships fostered between the Monastery of São Vicente de Fora and individuals, as well as the diversification and expansion of its rural heritage, which had a higher intensity near the city of Lisbon. Tracing back from the conquest of Lisbon and the foundation of the monastery, in the middle of the twelfth century, conducting an analysis on the processes of formation and structuration of monastic heritage, as well as on the mechanisms and strategies of patrimony acquisition and, lastly, on rural property composition. Afterwards, it presents the results, predominantly in rural landscape, in a descending order, are bread farms, vineyards and olive groves, and other type of rural properties, as much as of means of processing: mills and watermills, wine and olive presses, and ovens. It concludes that the Monastery acquired and owned a concentrated heritage mostly in the region of Lisbon, although its influence reached a national level due to the rights and privileges that it possessed in the kingdom.
\end{abstract}

Keywords: Medieval History. Monastery of São Vicente de Fora. Rural Heritage. Rural Heritage. Rural landscape. Portugal. 12th-13th centuries.

\footnotetext{
${ }^{1}$ Artigo submetido à avaliação em janeiro de 2017 e aprovado para publicação em maio de 2017.
} 
Outros Tempos, vol. 14, n. 23, 2017 p. 240 -259. ISSN:1808-8031

Resumen: El presente estudio, de naturaleza cualitativa y apoyado en investigación documental, analiza el sistema de organización económica y la gestión del aro rural, en particular la evolución de las relaciones que se establecieron entre el Monasterio de San Vicente de Fora y los particulares, así como La diversificación y la expansión de su patrimonio rural, más intensas al redor de la ciudad de Lisboa. Parte de la conquista de Lisboa y de la fundación del Monasterio, a mediados del siglo XII, siguiendo un análisis del proceso de formación y estructuración del patrimonio monástico, así como de las formas y estrategias de adquisición patrimonial, terminando con la composición de la propiedad rural. A continuación se presentan los resultados, predominando en el paisaje rural, por orden decreciente, las hereditates de "pan", las viñas y los olivares, junto a otro tipo de propiedades rurales, así como de los medios de transformación: molinos y aceñas, lagares de vino y aceite y hornos de pan. Concluye que el Monasterio había adquirido y poseía un patrimonio concentrado en la región de Lisboa, a pesar de su influencia extendida a nível nacional, en virtud de los derechos y los privilegios que poseía en el reino.

Palabras clave: Historia Medieval. Monasterio de San Vicente de Fora. Patrimonio Rural. Propiedad rural. Paisaje rural. Siglos XII-XIII.

\section{Introdução}

Desde o início da década de 40 do século XII, Lisboa, então sob domínio árabo-islâmico, vivia sob a ameaça de um ataque cristão proveniente do Norte. A conquista de Lisboa já havia sido tentada em 1140, testemunhando-a a Chronica Gothorum $^{2}$, ou 1142, data registada em A Conquista de Lisboa aos Mouros ${ }^{3}$, ou talvez em ambas as datas, pois já por diversas vezes, nos últimos anos, tinham tentado tomar a cidade, com a ajuda dos Cruzados. Em 1147, a conquista de Lisboa voltou a ser um dos objetivos de Afonso Henriques, que já se autointitulava de Rex, desde o Verão de 1139, ainda que o título apenas viesse a ser reconhecido pelo imperador Afonso VII de Leão em 1143 e pelo papa Alexandra III, em $1179^{4}$.

O cerco a Lisboa teve início em 1 de julho, durando aproximadamente 4 meses, caindo a cidade nas mãos dos cristãos em outubro de 1147, consumando-se a sua rendição a 21 do referido mês, com a suspensão dos ataques e a entrega de cinco reféns ao rei português. O Indiculum refere o dia 25 de outubro como o dia da entrada na cidade conquistada, data que ainda hoje se comemora. Contudo, a Chronica Gothorum antecipa esse momento para o dia 24 do mesmo mês (IX Calendas November), SextaFeira. O Relato do Cruzado Inglês refere apenas que a saída dos mouros da cidade se

2 HERCULANO, Alexandre. Portugaliae Monumenta Histórica: scriptores. Reprod. fac-similada. Lisboa: Academia das Ciências, 1969. v. 1, fasc. 1. p. 13-14.

${ }^{3}$ NASCIMENTO, Aires A. A conquista de Lisboa aos Mouros: relato de um Cruzado. Ed. trad. e notas de Aires Augusto Nascimento; Int. de Maria João Branco. Lisboa: Vega, 2001. p. 85

${ }^{4}$ MATTOSO, José. D. Afonso Henriques. [Lisboa]: Círculo de Leitores, 2006. 
Outros Tempos, vol. 14, n. 23, 2017 p. 240 -259. ISSN:1808-8031

iniciou no sábado, prolongando-se até quarta-feira ${ }^{5}$, devendo considerar-se a data de consumação da rendição, uma vez que os dias seguintes serviram apenas para estabelecer a combinação dos pormenores da entrada dos cristãos na cidade. A conquista de Lisboa integrou-se na Segunda Cruzada, respondendo a um pedido de auxílio de Afonso Henriques a Bernardo de Claraval $^{6}$, que assegurara a sua intercessão a favor dessa participação, no momento em que pregava a Cruzada nos Países Baixos e no Império. A ligação a Cister tornara-se, assim, mais um trunfo nas intenções de Afonso Henriques, que passavam pela autonomia e independência do reino. O jogo entre as dioceses de Braga (reino de Portugal) e Compostela (Galiza), a vassalagem à Santa Sé, as conquistas de território islâmico a Sul, as extensas concessões aos Templários, a fundação do mosteiro regrante de Santa Cruz de Coimbra, no qual se filiaria, e, por volta de 1160, a reforma do mosteiro de São Vicente de Fora, numa opção pelos Crúzios em detrimento dos Premonstratenses, bem como o auxílio dos Cruzados e a sua integração na Segunda Cruzada inserem a conquista de Lisboa num plano uma estratégico gizado por Afonso Henriques na procura do reconhecimento do título de rex, dando aos acontecimentos de 1147 uma dimensão supranacional ${ }^{7}$.

$\mathrm{O}$ reino ia-se formando, estendendo-se o território a Sul conquistado ao Andalus, investindo no reconhecimento interno e externo desse poder. Conquista do território que se fazia, paralelamente à da independência, contribuindo ambas para a legitimação do novel Rex. Para tal, D. Afonso Henriques apoiou-se em diversos conselheiros, nos movimentos monásticos reformistas de então, nomeadamente nos Cistercienses e Regrantes, cuja materialização da aliança seria mais visível na conquista de Lisboa, um acontecimento de enorme relevo e intensa «propaganda».

\footnotetext{
${ }^{5}$ SILVA, Carlos Guardado da. O Mosteiro de S. Vicente de Fora: Fundação, organização interna e património rural: séculos XII-XIII. Olisipo: Boletim do Grupo, Amigos de Lisboa, n. 13, v. 2, p. 29, jul./dez. 2000.

${ }^{6}$ LIVERMORE, H. The 'Conquest of Lisbon' and its Author. Portuguese Studies. 1990, n. 6, p. 7-12; PHILLIPS, J. St. Bernard of Clairvaux, the Low Countries and the Lisbon Letter of the Second Cruzade. Journal of Ecclesiastical History. 1997, 48, p. 494-497; LECLERCQ, J. et al. (Ed.). Sancti Bernardi Opera. Roma, v. 8, n. 308, 1977.

7 BARBOSA, Pedro Gomes. S. Bernardo e a Independência de Portugal. In: ENCONTRO DE ALCOBAÇA E SIMPÓSIO DE LISBOA: Centenário do Nascimento de S. Bernardo, 9., 1991, Braga. Actas... Braga: Universidade Católica Portuguesa, 1991, p. 348; SILVA, Carlos Guardado da. O Mosteiro de S. Vicente de Fora: a comunidade regrante e o património rural: séculos XII-XIII. Lisboa: Colibri, 2002, p. 33 e ss; PHILLIPS, J. St. Bernard of Clairvaux, the Low Countries and the Lisbon Letter of the Second Cruzade. Journal of Ecclesiastical History, n. 48, p. 495-496, 1997; NASCIMENTO, A. A conquista de Lisboa aos Mouros: relato de um Cruzado. Ed. trad. e notas de Aires Augusto Nascimento; Int. de Maria João Branco. Lisboa: Vega, 2001, p. 34; 161; SILVA, Carlos Guardado da. Lisboa Medieval: a organização e a estruturação do espaço urbano. Lisboa: Colibri, 2008.
} 
Outros Tempos, vol. 14, n. 23, 2017 p. 240 -259. ISSN:1808-8031

Com o presente estudo, procuramos compreender o sistema de organização económica e a gestão do aro rural, nomeadamente a evolução das relações que se estabeleceram entre o Mosteiro e os particulares, a diversificação e a expansão do seu património rural, independentemente das formas de aquisição, de domínio da propriedade e de criação de rendas, tendo por base o fundo arquivístico do mosteiro de São Vicente de Fora (1. ${ }^{\mathrm{a}}$ e 2. ${ }^{\mathrm{a}}$ incorporações), conservado no Arquivo Nacional Torre do Tombo $^{8}$, em Lisboa (Portugal).

\section{A fundação do Mosteiro}

A fundação do mosteiro de São Vicente de Fora surgiu, segundo a tradição, no cumprimento de um voto de D. Afonso Henriques, caso conquistasse a cidade, ou em honra dos grandes homens $e$ dalto sangue, que pereceram na conquista ${ }^{9}$, tendo sido lançada a primeira pedra a 21 de novembro de $1147^{10}$. O local escolhido para a fundação do Mosteiro, imediata à conquista de Lisboa, teve uma ocupação de enterramentos bastante antiga, recuando pelo menos ao período visigótico ${ }^{11}$.

A escolha da fundação de um mosteiro em Lisboa, de invocação a São Vicente, não é alheia ao facto de existir uma associação estreita entre o movimento Crúzio e a veneração a santos que a tradição moçárabe conservara. São Vicente é um desses santos hispânicos, do século IV, cujo culto fora mantido pelos moçárabes no cabo de seu nome, no extremo ocidente do Algarve, desde o século IX, tendo por base a

\footnotetext{
${ }^{8}$ ANTT - Mosteiro de São Vicente de Fora (Lisboa). Primeira Incorporação: maço 1, n. ${ }^{\circ}$ 1-45; maço 2, n. ${ }^{\circ}$ 1-49; maço 3, n..$^{\circ}$ 1-54; maço 4, n. ${ }^{\circ}$ 1-24, 42; maço 5, n. ${ }^{\circ}$ 3. Segunda Incorporação: maço 23 - B, C, E, G, H, I, J; maço 33, fl. 25; caixa 1 , n. ${ }^{\circ}$ s $15,30,240-242,246,254,257$; caixa 5 , n. ${ }^{\circ} 47$; caixa 31 , maço 7 , n. ${ }^{\circ}$ 5; caixa 31, maço 71, n. ${ }^{\circ} 1-3,9-19$, R. $^{\circ} 1-4$.

9 CRONICA DA FUNDAÇAM DO MOESTEYRO DE SAM VICENTE DOS CONEGOS REGRANTES: DA HORDEM DO AURELIO DOCTOR SANCTO AUGUSTINHO: EM A CIDADE DE LIXBOA. Porto: Imprensa Portugueza, 1873; SANTA MARIA, N. Chronica da Ordem dos conegos regrantes do patriarcha S. Agostinho. Lisboa: Officina de Joam da Costa, 1668, p. 229-230; CRUZ, Marcos da. Catálogo dos priores do moesteyro de S. Vicente de Fora de Lixboa. Coimbra: Biblioteca da Universidade, manuscrito, 632 f., 625 v.;

${ }^{10}$ LIMA, D. (Ed.). História dos mosteiros conventos e casas religiosas de Lisboa no qual se dá notícia da fundação e fundadores das instituições religiosas, igrejas, capelas e irmandades desta cidade. Lisboa: Oficina das Gráfica Santelmo, 1950, tomo I, p. 5.

${ }^{11}$ SANTA MARIA, N. Chronica da ordem dos conegos regrantes do patriarcha S. Agostinho. Lisboa: Officina de Joam da Costa, 1668, p. 112; FERREIRA, F. O mosteiro de S. Vicente de Fora: subsídios para a reconstituição da sua fisionomia. Revista Municipal de Lisboa. Lisboa: Câmara Municipal, 1983, ano 44, 2. série, n. 4, 2 trimestre 1983; ano XLVI, $2^{a}$ série, n. 12 ,2. trimestre, 1985, p. 3-12; FERREIRA, F. O mosteiro de S. Vicente de Fora: subsídios para a reconstituição da sua fisionomia. Revista Municipal de Lisboa. Lisboa: Câmara Municipal, 1985, ano 46, 2. série, n. 12, 2. trimestre;
} 
Outros Tempos, vol. 14, n. 23, 2017 p. 240 -259. ISSN:1808-8031

crença de aí terem sido enterradas as verdadeiras relíquias do santo, segundo a versão portuguesa.

Sendo o Mosteiro uma fundação premonstratense, não demorou a ser reformado, dada a influência de João Peculiar, arcebispo de Braga, e de São Teotónio, prior do Mosteiro de Santa Cruz de Coimbra, ambos representantes do cristianismo franco, e este o principal confidente de Afonso Henriques, que sabendo antecipadamente dos projetos do monarca, permanecia em oração enquanto se conquistava a cidade de Lisboa $^{12}$. A fixação do culto vicentino na cidade parece, porém, dever-se mais a corpos sociais aí presentes do que à iniciativa do primeiro monarca. A devoção a São Vicente dever-se-ia, muito provavelmente, à emigração franca para o ocidente peninsular.

A fundação do Mosteiro e a sua estruturação, nos séculos XII e XIII, corresponde ao tempo de formação do reino de Portugal, tendo a canónica adquirido, paulatinamente, uma organização interna eficaz, numa imitação da sua casa-mãe - o mosteiro de Santa Cruz de Coimbra - indissociável do vasto património que viria a adquirir, fruto de uma eficaz gestão. Património cuja extensão compreendia quase todo o território nacional, desde Silves até à Guarda, apesar de se encontrar intensamente marcado por uma implantação e concentração de propriedades fundiárias na região de Lisboa, entre Sesimbra, Santarém, Torres Vedras e Sintra, espaço de maior influência espiritual da canónica ${ }^{13}$.

\section{0 património rural}

Desde a sua fundação, os Priores do mosteiro de São Vicente incutiram uma política de aquisições intensa, acabando por dotar a canónica de um extenso e valioso património, que acabaria por definir as grandes áreas de expansão territorial, assim como os espaços de influência do mosteiro, que ultrapassavam largamente as fronteiras físicas das suas propriedades. Na dependência direta da Santa Sé, São Vicente obteve a libertas romana, que o tornava isento da autoridade episcopal, exercendo jurisdição

\footnotetext{
${ }^{12}$ NASCIMENTO, Aires A. (Ed.). Hagiografia de Santa Cruz de Coimbra. Lisboa: Colibri, 1998. p. 189; MARQUES, José. A realidade da Igreja no tempo de S. Teotónio. sep. da Revista da Faculdade de Letras. II série, v. 7. Porto: Faculdade de Letras, 1990. p. 26.

${ }^{13}$ SILVA, Carlos Guardado da. Fundação, organização interna e gestão do património na Idade Média. In: SALDANHA, Sandra Costa (Coord.). Mosteiro de São Vicente de Fora: arte e história. Lisboa: Centro Cultural do Patriarcado de Lisboa, 2010. p. 11-33.
} 
Outros Tempos, vol. 14, n. 23, 2017 p. 240 -259. ISSN:1808-8031

própria nos seus territórios, e nomeadamente em Alenquer, São Julião do Tojal, São Cucufate e Castelo Mendo. Esta questão suscitaria, desde muito cedo, um litígio estrutural entre o prior e convento de São Vicente e o bispo da cidade de Lisboa, razão que levaria o prior-mor a procurar sucessivamente a confirmação deste privilégio, quer junto do bispo, quer junto do papa. A canónica conseguiria, porém, o reconhecimento de uma liberdade plena tornando-se uma instituição ab omni episcopali iure et exactione salva sedis apostolice auctoritate.

Deste modo, a jurisdição e autoridade do prior-mor cresciam no espaço físico e espiritual, obtendo direitos de apresentação nas igrejas de São Julião do Tojal e Arruda, da diocese de Lisboa, São Julião da Guarda e Santa Maria de Pousada, aos quais se juntavam os privilégios do monarca e de alguns membros da família real, assim como a doação episcopal do lugar de Lagos, com direitos e privilégios, a igreja de São Mateus de Montemor-o-Novo, o mosteiro e a paróquia de São Cucufate, entre muitos outros que faziam estender o rol dos seus direitos ${ }^{14}$.

O prior e o convento foram constituindo, ao longo da Idade Média, um património concentrado, embora descontínuo, em locais de acessibilidade fácil, onde a distância entre o mosteiro e os seus imóveis permitisse uma gestão mais eficaz e controlada por aquele. Propriedades que se situavam, sobretudo, no termo de Lisboa, embora possuíssem alguns bens nos termos vizinhos de Sintra, Torres Vedras, Alenquer, Povos, Santarém e Sesimbra. A fertilidade das terras, a proximidade das linhas de água e das vias de comunicação, que tornavam mais fáceis e rápidos os acessos aos centros urbanos, e nomeadamente a Lisboa, mercado preferencial para os produtos excedentários, foram decerto fatores decisivos na definição da política de gestão do património fundiário de São Vicente de Fora.

A primeira aquisição que conhecemos data de 1162, através de uma compra efetuada por D. Godinho, primeiro prior-mor do cenóbio, a Paio Aires, junto a São Martinho, na cidade de Lisboa, pelo preço de 19 morabitinos ${ }^{15}$. Todavia, não se trata da primeira aquisição da canónica de São Vicente, o que parece testemunhar igualmente a Cronica da fundação do mosteiro:

[...] e visto per elrey o dito acordo, tomou entom pera sy por sua camara o dito moesteyro de Sam Vicente de fora, dotandoo de grandes

\footnotetext{
${ }^{14}$ SILVA, Carlos Guardado da. O Mosteiro de S. Vicente de Fora: a comunidade regrante e o património rural: séculos XII-XIII. Lisboa: Colibri, 2002. p. 174-179.

${ }^{15}$ ACABADO, M. Inventário de compras do real mosteiro de S. Vicente de Fora: cartulário do séc. XIII. Coimbra: Arquivo de Bibliografia Portuguesa, 1969, n. 53-56, p. 11.
} 
Outros Tempos, vol. 14, n. 23, 2017 p. 240 -259. ISSN:1808-8031

e nobres possisões de terras no seu reyno, em tal maneyra que o dito
moesteyro se podesse manter honradamente $[\ldots]^{16}$.
$[\ldots]$ e deu-lhe grandes herdades e outras muytas cousas pera honra e
repairamento e mantimento do dito moesteyro e dos servidores del, e
esto porque o serviço de Deus fosse feito compridamente sem outro
embargo que ouuessem dos beens temporaes $[\ldots]^{17}$.

Nos primeiros tempos, parece notória a procura de aquisição de bens em locais próximos do Mosteiro. Todavia, verifica-se uma rápida tendência de expansão, em direção aos campos de Alvalade, Telheiras, Tojal, Bucelas, Romeira e Vila Longa, ocupando as férteis e soalheiras encostas da península de Lisboa, assim como os fertilíssimos vales de aluvião, que ladeavam a ribeira de Odivelas, desde ocidente, até Alpriate.

O termo de Alenquer também mereceu, desde cedo, uma atenção especial por parte dos priores de São Vicente, razão que explica o interesse da canónica em comprar, logo em 1173, uma herdade na Torre de São Vicente (Cadafais), seguindo-se outras aquisições que contribuíram para um aumento do património rural do mosteiro naquele espaço. Interesse acrescido se tivermos em conta que todas as aquisições naquele local foram objeto de compra, onde as doações estiveram ausentes.

A constituição do seu património a sul do Tejo é mais tardia, datando a primeira aquisição de 1230 , o que parece natural se atendermos que até à conquista de Alcácer do Sal, em 1217, esta não era uma região segura. As propriedades do mosteiro nesta região tendem a concentrar-se no termo de Sesimbra, junto à Ribeira de Coina, atingindo preços bastante elevados. Para este facto terão certamente contribuído diversos fatores, como a existência do curso de água e de um moinho, bem como a proximidade da uia publica que uadit ad Palmela e a já referida conquista de Alcácer, que terá permitido inflacionar o preço dos terrenos.

O Mosteiro viria a adquirir propriedades na Beira Alta, no termo de Castelo Mendo, porém, por doação. Pois é notório um grande desinteresse por parte da canónica na região, razão que explica o facto de não ter comprado qualquer propriedade naquele espaço. Duas doações apenas, nos séculos XII e XIII, mas um facto importante, que testemunha a fama e o prestígio do Mosteiro e do culto vicentino mais a norte, talvez explicável pela influência espiritual, e não só, que Santa Cruz de Coimbra exercia na região, onde possuía igualmente propriedades. Todavia, podemos questionar a razão de

\footnotetext{
${ }^{16}$ CRONICA da fundaçam do moesteyro de Sam Vicente dos conegos regrantes: da hordem do aurelio doctor Sancto Augustinho: em a cidade de Lixboa. Porto: Imprensa Portugueza, 1873. p. 37.

${ }^{17}$ Ibid., p. 41.
} 
Outros Tempos, vol. 14, n. 23, 2017 p. 240 -259. ISSN:1808-8031

não ter sido este Mosteiro a receber as propriedades de Paraisal e Freixo, que engrossariam o rol de bens da canónica de São Vicente de Fora. Este é um problema que se nos levanta, ao qual os documentos não nos dão resposta, silenciando as causas mais profundas, por vezes subjetivas, que poderão estar na sua origem.

Em suma, a constituição do património rural de São Vicente de Fora cresceu, sobretudo, através das aquisições por compra que constituem inicialmente a principal forma jurídica de aquisição de propriedades. Compras que se deveram ao interesse da canónica no estabelecimento de áreas de influência e exploração rentáveis, ocupando os solos mais ricos e férteis, com uma grande riqueza de recursos naturais, que lhe permitia a obtenção de melhores e mais rentáveis produções, fazendo crescer os lucros do Mosteiro. Aquisições por compra que tendem a diminuir à medida que nos afastamos do Mosteiro, sobretudo para além do espaço do Tojal-Bucelas-Alpriate, a norte, evidenciando uma clara intencionalidade de concentrar o seu património junto do centro administrador, como já havia notado Robert Durand, para os séculos XII e XIII:

La localisation du domaine de Saint-Vicent-Hors-les-Murs, à Lisbonne, est
beaucoup plus aisée à circonscrire que celle des possessions d'Alcobaça:
quatre acquisitions sur cinq sont situées dans le "termo" de Lisbonne, zone
don't les limites sont encore assez floues, mais qui semble affecter la forme
d'un rectangle don't le grand côté oriental serait limité par le Tage sur une
longueur d'une trentaine de kilomètres, la limite occidentale se situant à mi-
distance entre Lisbonne et Sintra. Dans ce champ dèjá réduit, on note encore
quelques zones d'implantation plus dense: outre Lisbonne elle-même, les
lieux-dits contigus de Bucelas, Tojal et Alpriate. Sans quitter l'Estrémadoure,
il semble que, à partir de la fin du XIIe siècle, les chanoines de Saint-Vicent
aient cherché à se constituer un autre centre domanial près de Alenquer, au
lieu-dit Torre de São Vicente, mais jusqu'en 1250 ce centre reste très
secondaire ${ }^{18}$.

A estas juntaram-se as doações, como forma jurídica de obtenção de propriedades do mosteiro, enriquecendo o seu património, e que se tornarão o grande meio de aquisição de bens da canónica, numa segunda fase, quando se encontravam já estruturadas as áreas de expansão territorial do seu domínio.

Algumas doações revelaram-se particularmente importantes no estabelecimento de núcleos fundamentais do domínio senhorial de São Vicente de Fora, de que é exemplo da herdade do Tojal, entregue por D. Afonso II, em 1218. Uma doação que marcou, desde então, uma das grandes áreas de influência e domínio

\footnotetext{
${ }^{18}$ DURAND, Robert. Les campagnes portugaises entre Douro et Tage aux XIIe et XIIIe siècles. Paris: Fundação Calouste Gulbenkian, 1983. p. 318-319.
} 
Outros Tempos, vol. 14, n. 23, 2017 p. 240 -259. ISSN:1808-8031

efetivos de São Vicente nas várzeas entre Loures e Frielas até Alpriate, passando por Bucelas e Romeira. Outras partiram da necessidade de garantir a subsistência que a posse da terra já não permitia, quer por exaustão, que por falta de mão de obra, quer pela incapacidade de efetuar o pagamento de dívidas acumuladas ao longo de vários anos agrícolas improdutivos e, não menos importante, a crença na capacidade de intervenção dos cónegos regrantes perante o divino, face aos castigos que se abatiam sobre o mundo pecador.

As herdades e as vinhas constituíam, invariavelmente e de forma destacada, o grande conjunto de propriedades do mosteiro, permitindo-lhe assegurar a abundância de pão e vinho. As herdades, localizadas em terrenos de aptidão agrícola diversificada, estavam especialmente associadas à produção de cereais e leguminosas. Às terras de "pão" e vinho, juntavam-se as árvores de fruto e as oliveiras, dada a importância do azeite que, para além da sua riqueza vegetal e alimentar, se impunha no ofício divino.

Deste modo, o processo de formação e estruturação do património de São Vicente efetuou-se, sobretudo, durante o século XII e as três primeiras décadas do século XIII, correspondendo aos priorados de D. Paio Gonçalves (1172-1208), D. Pedro (1205-1211), D. Estêvão (1211-1221) e D. Gonçalo (1221-1255/8).

As diferentes conjunturas políticas e económicas, bem como a menor ou maior influência e dinâmica de cada prior-mor influenciariam a maior ou menor disponibilidade financeira do Mosteiro para adquirir novas propriedades. A sua projeção dependia igualmente da ação de cada prior-mor, assim como da política de gestão do património material e espiritual que, em cada momento, aquele imprimia à canónica.

As permutas de propriedades, instrumentos caraterizadores de uma gestão patrimonial racional dos bens patrimoniais do Mosteiro, são escassas, evidenciando uma estratégia de aquisição dum património fundiário concentrado desde o seu início.

\section{A composição da propriedade}

\subsection{A paisagem rural}

\subsubsection{As herdades de "pão"}

O pão, o vinho e o azeite formavam a trilogia da alimentação no espaço mediterrânico, cabendo um lugar de destaque, na produção agrícola medieval, aos 
Outros Tempos, vol. 14, n. 23, 2017 p. 240 -259. ISSN:1808-8031

cereais e ao vinho, invariavelmente presentes em todas as refeições, como alimentosbase que eram da nutrição de então ${ }^{19}$.

Os campos de cereal parecem dominar a área de ocupação do ager (espaço agricultado), sobretudo se atendermos que as designadas hereditates, quintas e casais, eram, na maior parte das vezes, ocupadas por terras de "pão", isto é cereal panificável. Todavia, as terras de cereal não eram ocupadas por este tipo de culturas exclusivamente, associando-se ao plantio da vinha e à cultura da oliveira ${ }^{20}$. Na documentação existente no cartório do Mosteiro de São Vicente, encontramos apenas referências ao trigo, alimento que assegurava a subsistência básica, servindo de moeda na compra de propriedades. Em março de 1172, Maria Armigiz e suas filhas e genros venderam ao Mosteiro uma herdade junto à igreja de São Vicente, pelo preço de um morabitino e um quarteiro de trigo. Em julho de 1190, Miguel Afonso e sua mulher Maria Gonçalves venderam uma herdade ao Mosteiro pelo preço de nove morabitinos e um quarteiro de trigo. E no mesmo ano, a Canónica comprou um tojal em Bucelas-Romeira a Paio Bermudes por duas morabitinadas de tritico in tempore quo uendebantur VII alqueires pro uno morabitino. Por último, temos uma referência indireta à sua produção através de uma carta de doação de uma herdade no lugar da várzea, termo de Torres Vedras, com a condição de ser dado ao seu doador, em vida, 5 alqueires de trigo. Sendo uma cultura praticada intensamente por todo o país, os cereais encontravam nesta região do vale do Tejo e sobretudo junto ao curso de água do Trancão, dado os elevados índices de fertilidade das terras de aluvião e a abundância de água que permitiam um sistema de regadio, condições excecionais ao seu desenvolvimento. A referência exclusiva ao trigo nos documentos de São Vicente poderá explicar-se pelo facto de este ser o cereal dominante na Estremadura, situação idêntica à encontrada por José Varandas nas propriedades do Mosteiro de Santa Maria de Almoster. Uma outra explicação poderá relacionar-se com o facto de este ser um cereal de melhor qualidade, o "pão" por excelência, preferido por agricultores e senhorios, ocupando as melhores terras e garantindo grande parte do pagamento das rendas. E destinava-se ao mercado interregional, como certamente verificamos na doação da herdade Várzea, no alfoz de Torres Vedras.

\footnotetext{
${ }^{19}$ GONÇALVES, Iria. Acerca da alimentação medieval. In: Id. Imagens do mundo medieval. Lisboa: Livros Horizonte, 1988, p. 203.

${ }^{20}$ MARQUES, António Henrique de Oliveira. Introdução à história da agricultura em Portugal: a questão cerealífera na Idade Média. 3. ed. Lisboa: Cosmos, 1978. p. 98-99.
} 
Outros Tempos, vol. 14, n. 23, 2017 p. 240 -259. ISSN:1808-8031

Quanto a outros cereais, não possuímos quaisquer outras informações na documentação avulsa da Canónica, referente a este período. Todavia, o Foral de São Julião do Tojal, de 1258, regista o trigo e o milho como principais culturas de pão na região. A Idade Média conheceu o trigo de Inverno (triticum vulgare hibernum), o trigo túrgido (triticum turgidum) e o far adoreum, qualidade de trigo duro, que designava o triticum dicoccum e o trigo espelta.

Mapa 1: Herdades

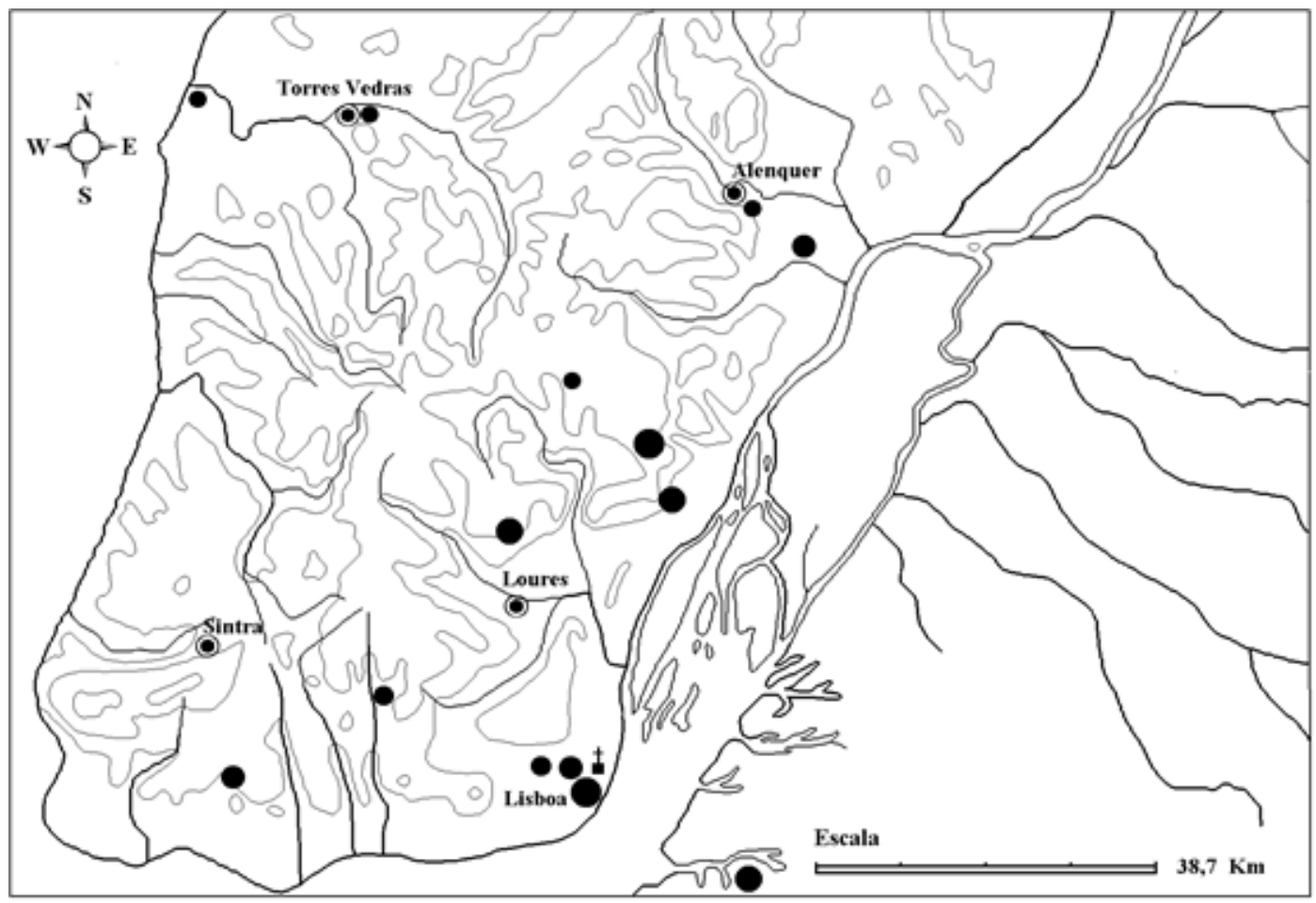

\section{Legenda:}

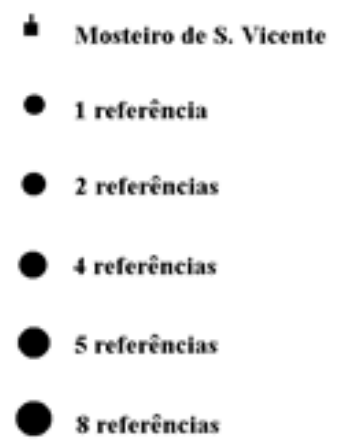

Fonte: Elaborado pelo autor. 
Outros Tempos, vol. 14, n. 23, 2017 p. 240 -259. ISSN:1808-8031

Outro testemunho da existência de cereais é comprovado pela referência a unidades transformadoras de cereal. O Mosteiro encontrava-se na posse de duas azenhas e nove moinhos. Curiosamente, todos estes meios de transformação do pão foram adquiridos por doação. É a inexistência de compras destes bens patrimoniais reveladora de um desinteresse por parte da Canónica? Preferimos outra explicação relacionada com os custos destes meios. Pois o moinho era uma construção bastante onerosa e complexa, exigindo uma grande capacidade económica para os mandar construir. Tanto a sua construção como a sua manutenção exigiam mão de obra especializada e materiais caros, como o ferro e a madeira ${ }^{21}$.

Mapa 2: Azenhas e Moinhos

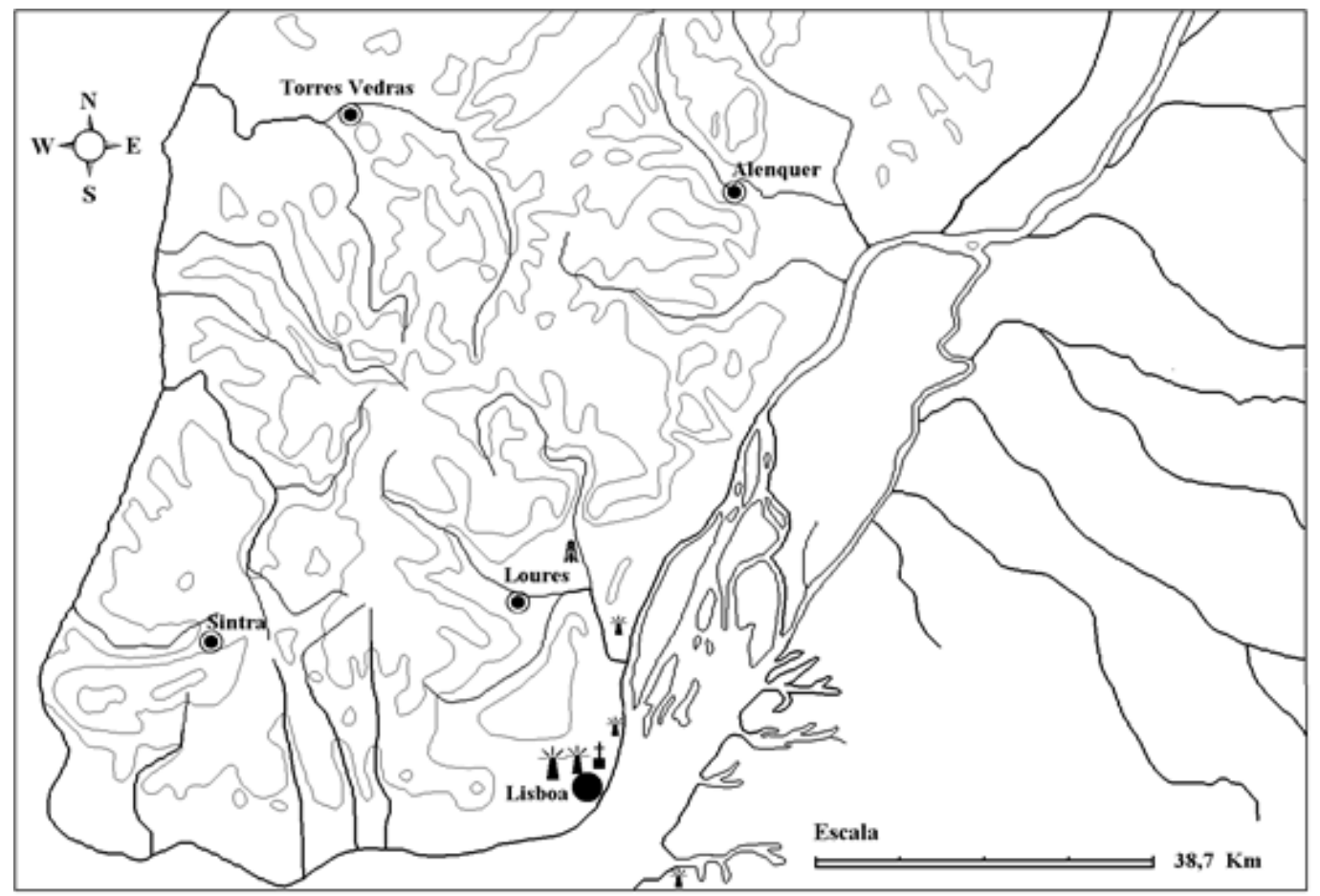

\footnotetext{
${ }^{21}$ BARBOSA, Pedro Gomes. Os moinhos de Santa Maria de Alcobaça-Leiria: séc. XIII. Documentos Lugares e Homens: Estudos de História Medieval. Lisboa: Edições Cosmos, 1991. p. 46 e ss.
} 
Outros Tempos, vol. 14, n. 23, 2017 p. 240 -259. ISSN:1808-8031

\section{Legenda: \\ $\$$ Mosteiro de S. Vicente \\ A Azenhas -2 referênncias \\ Moinhos - 1 referência \\ I Moinhos - 3 referêneias \\ 1. Moinhos -4 referêneias}

Fonte: Elaborado pelo autor.

A aquisição de um moinho em Almofala, em fevereiro de 1192, é a primeira referência que possuímos a estes meios de transformação de "pão" na posse da Canónica. No entanto, assume relevo especial a doação ao Mosteiro de 7 moinhos, 3 na Pedreira e 4 na Serra, no termo de Lisboa, datada de dezembro de 1211. Lembramos, porém, que a referência a vários moinhos pode não implicar a existência de diversos edifícios, indicando apenas o número de rodas existentes num edifício, como notara António Vicente ${ }^{22}$.

O Mosteiro também se encontrava na posse de 1/2 forno para cozer o pão, perto de São Vicente. Aquisição que se deve a uma intencionalidade direta, dado ter resultado de uma compra que a Canónica efetuou a João Culuchi e sua mulher Ausenda Mendes e a Salvador Gonçalves e sua mulher Auroana Pires e filhos, em julho de 1189. Certamente que outros fornos existiriam nas quintas e casais que não aparecem referidos, talvez por fazerem parte de uma unidade de produção autossuficiente, cujos bens eram explorados em conjunto, como refere Maria Filomena Andrade ${ }^{23}$. Deste modo, a Canónica, associando à posse da terra o controlo dos meios de transformação, ia alargando e fortalecendo o seu poder.

A cultura cerealífera na Idade Média encontrava-se intimamente relacionada com uma revolução técnica, no que diz respeito à utilização da terra e aos seus utensílios. O sistema trienal veio substituir o tradicional afolhamento bienal, provocando uma alteração significativa na alternância das colheitas.

\footnotetext{
${ }^{22}$ VICENTE, António Maria Balcão. Santa Maria de Aguiar: um mosteiro de fronteira: património rural e paisagem agrícola: séculos XII-XIV. Lisboa: policopiado, 1996, p. 188, nota 410. Prova de mestrado apresentada à Faculdade de Letras da Universidade de Lisboa.

${ }^{23}$ ANDRADE, Maria Filomena. O mosteiro de Chelas: uma comunidade feminina na baixa Idade Média: património e gestão. Cascais: Patrimonia Historica, 1996. p. 56.
} 
Outros Tempos, vol. 14, n. 23, 2017 p. 240 -259. ISSN:1808-8031

\subsubsection{As vinhas}

O vinho, elemento indispensável na liturgia cristã, era um importante suplemento na dieta alimentar do homem medievo, constituindo uma parte importante dos seus rendimentos ${ }^{24}$. Geralmente procuravam-se os locais junto aos cursos de água para o plantio da vinha, a fim de permitirem a irrigação da mesma, bem como o transporte da sua produção até ao mercado urbano.

A omnipresença da vinha, muitas vezes associada a outras culturas agrícolas, estende-se ao interior da cidade de Lisboa, misturando-se com os pomares e os quintais ${ }^{25}$. A sua cultura, dados os cuidados especiais e os difíceis trabalhos, obrigavam a uma mão de obra numerosa, razão por que procuravam implantar-se próximo das áreas habitadas.

As vinhas representavam $24 \%$ do total de aquisições por parte da Canónica de São Vicente, sendo o seu maior número na cidade de Lisboa e no aro rural imediatamente envolvente. Muitas das vezes, integravam unidades de exploração, os casais, geralmente habitados.

Mapa 3: As Vinhas

\footnotetext{
${ }^{24}$ PEREIRA, Isaías da Rosa. A vinha e o vinho em documentos medievais. $O$ vinho na história portuguesa: séculos XIII-XIX: ciclo de conferências. Porto: Fundação Engenheiro António de Almeida, 1983. p. 7.

${ }^{25}$ TRINDADE, Maria José Lagos; GASPAR, Jorge. A utilização do solo em torno de Lisboa na Idade Média e o modelo de Van Thunen. Boletim cultural da Junta Distrital de Lisboa. Lisboa: Junta Distrital, 1973-74. p. 7.
} 
Outros Tempos, vol. 14, n. 23, 2017 p. 240 -259. ISSN:1808-8031

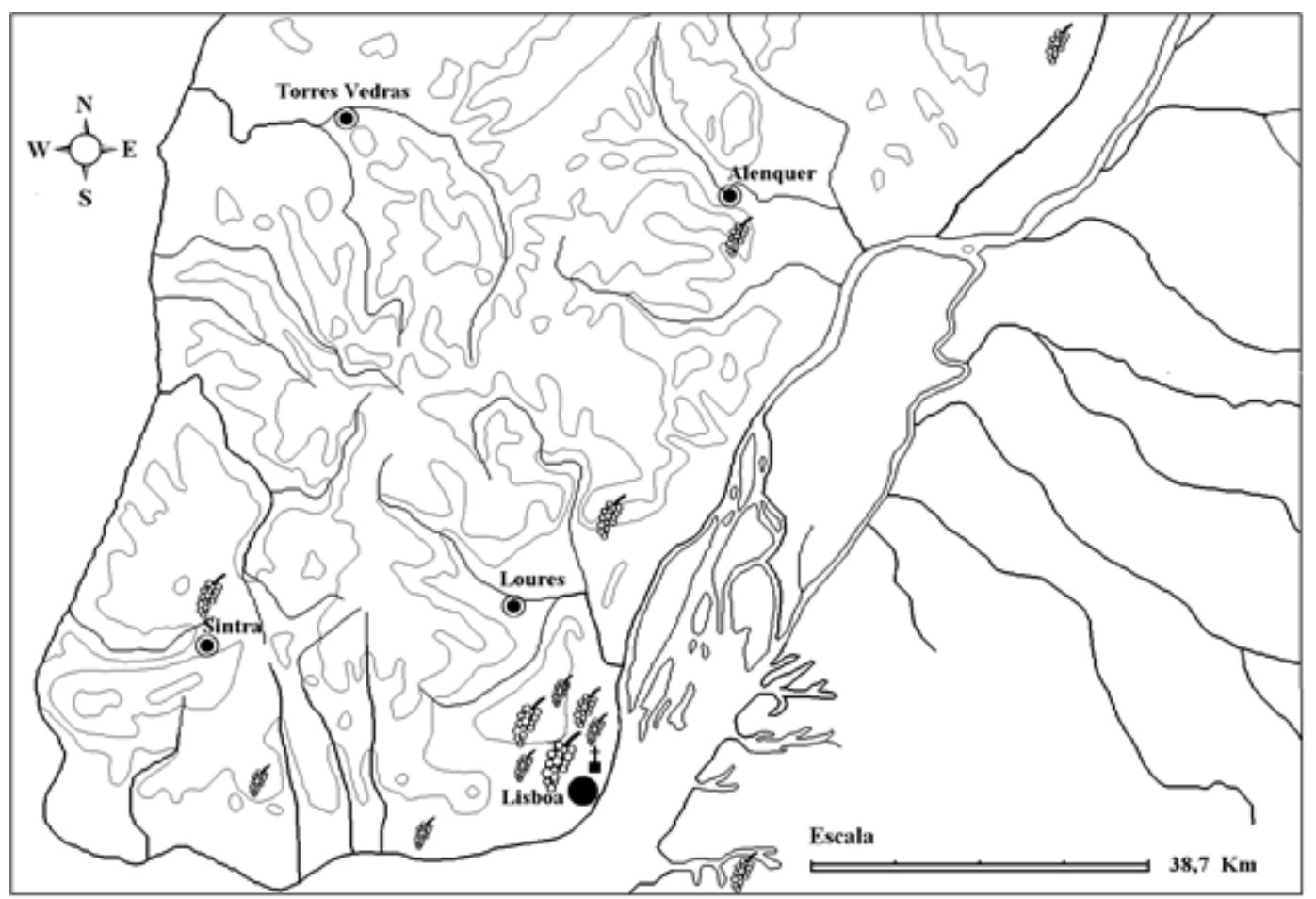

\section{Legenda:}

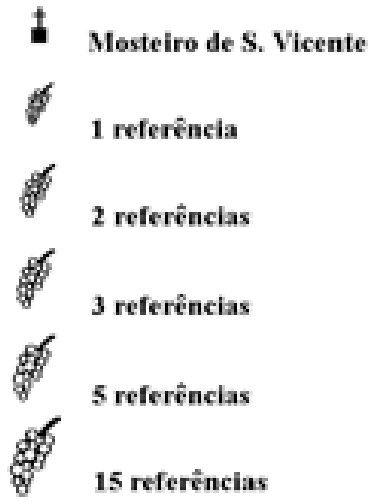

Fonte: Elaborado pelo autor.

As dificuldades sentidas no transporte do vinho contribuíam, também, para a aproximação da sua cultura aos meios urbanos. Todavia, não exigia terrenos tão férteis quanto os cereais, dando-se mesmo nas terras magras, arenosas e pedregosas, desde que expostas ao sol e abrigadas dos ventos fortes. Precisava de ser podada, empada, cavada e redrada, "desmamoada", enxofrada, "esborralhada", valada ou mesmo tapada com árvores, geralmente oliveiras. Este era o ciclo da cultura da vinha, que implicava uma atenção permanente e exigia o recurso a uma mão de obra vasta, fazendo diminuir o seu plantio à medida que se aumentava a distância dos centros habitacionais. Um conjunto de cuidados que mantinham a vinha rasteira, através de vigorosas podas anuais, 
Outros Tempos, vol. 14, n. 23, 2017 p. 240 -259. ISSN:1808-8031

tornando-se a uva rica de açúcar, o que asseguraria um vinho com elevado grau alcoólico.

A diversidade dos climas, dos solos, das castas de uvas, dos tratamentos dados à vinha, bem como dos processos de fabricação explica a grande variedade de tipos de vinho produzidos. Não possuímos qualquer referência às castas. Todavia, não andariam longe das castas galega, castelã, labrusca e mourisca, representadas nas propriedades do domínio do Mosteiro de Chelas.

O fabrico de vinho era feito em lagares, cuidadosamente conservados e reparados quando necessário. Quando o lagar era do convento, o foreiro tinha de pagar a lagaragem. O vinho obrigava a condições de conservação e armazenamento excecionais, devido ao facto de deteriorar-se rapida e frequentemente. Por isso, depois de fermentado, o vinho era armazenado nas várias adegas disseminadas pelas propriedades do Mosteiro e arrecadado em recipientes, todos de madeira e de diversas capacidades: os cascos, as cubas, os tonéis e as pipas.

Mapa 4: Adegas e lagares de vinho 
Outros Tempos, vol. 14, n. 23, 2017 p. 240 -259. ISSN:1808-8031

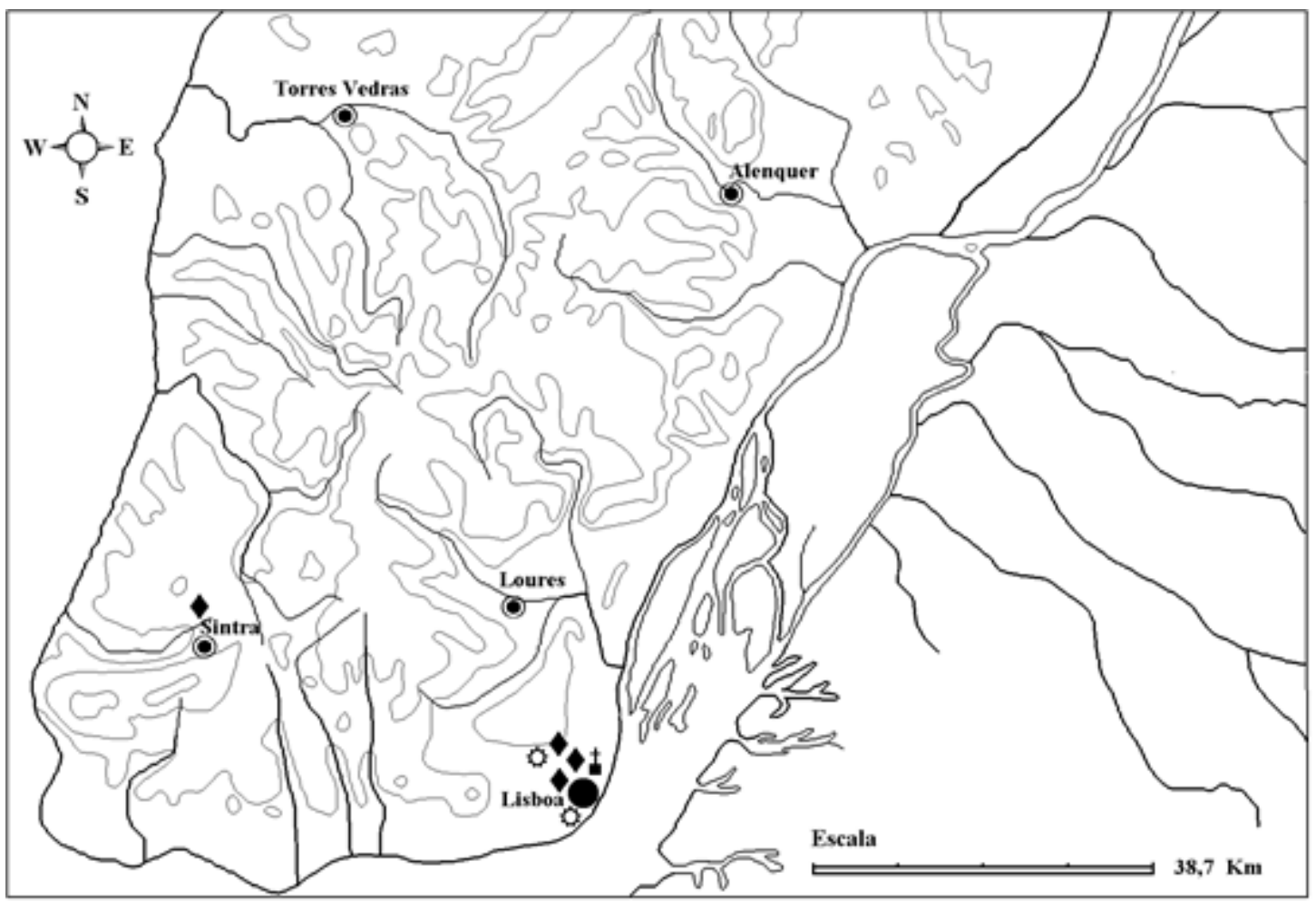

Legenda:

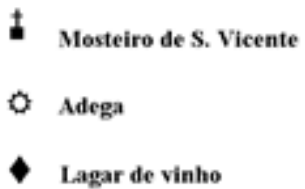

Fonte: Elaborado pelo autor.

\subsubsection{Os olivais}

As árvores e os arbustos tiravam melhor partido do solo e do clima do que os cereais, mais exigentes e sensíveis. Também hoje as raízes penetram fundo e aproveitam a humidade do subsolo. Agarram-se bem nas terras pedregosas e nos grandes declives e, uma vez a produzir, fazem-no por muito tempo, sem imobilizar uma parte da colheita na incerta sementeira de cada ano. Daí a larga expansão das plantações de árvores e arbustos, parte essencial do esforço agrário e não simples recurso complementar.

Conhecida no Ocidente da Ibéria, antes da conquista romana, a oliveira conta-se entre as poucas plantas cultivadas de origem mediterrânica. Cresce de preferência em terrenos calcários, dando-se em todos os solos. Todavia, não é 
Outros Tempos, vol. 14, n. 23, 2017 p. 240 -259. ISSN:1808-8031

indiferente ao clima. Requer Invernos moderados, chuva abundante na estação fria, temperatura não inferior a 18 graus durante a floração, estio quente, seco e prolongado $^{26}$. Para além da sua riqueza vegetal, cujo azeite era indispensável à Canónica e ao ofício litúrgico, a oliveira oferecia a lenha que iluminava e aquecia muitas casas.

Os olivais encontravam-se acompanhados pelos respetivos meios de transformação na paisagem: os lagares. Tarefa difícil é saber, na atualidade, se os lagares referidos na documentação eram de vinho ou de azeite. Todavia, temos um documento que refere explicitamente tratar-se de um lagar de azeite. A concentração de olivais era nítida em redor de Lisboa, tendo permanecido nos topónimos Olivais Sul e Olival Basto, associando-se, muitas vezes, à vinha e ao pomar. No conjunto das propriedades de São Vicente, os olivais ocupavam a quinta posição, depois das herdades, das vinhas, das casas e dos moinhos.

Mapa 5: Olivais e Lagares

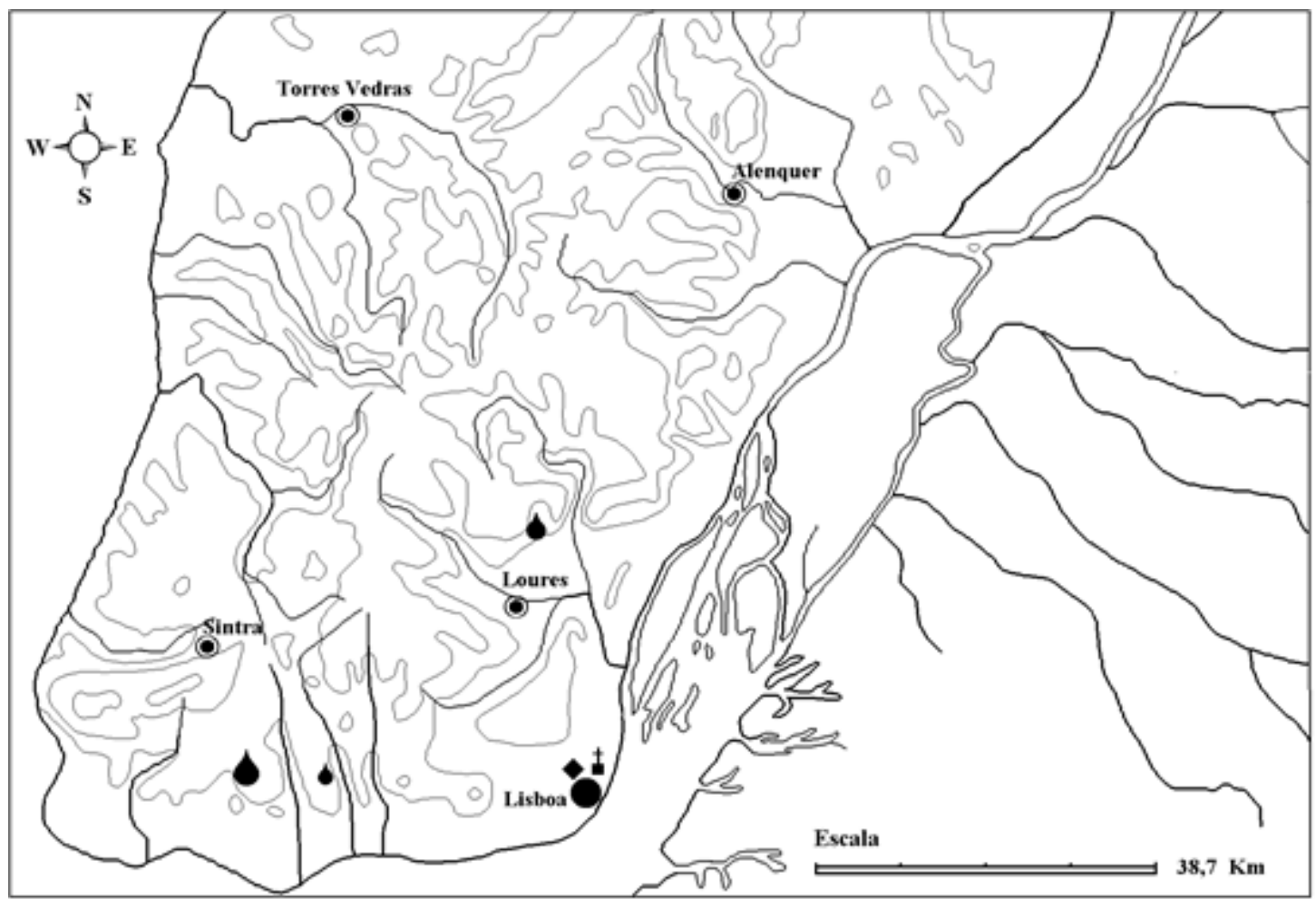

\footnotetext{
${ }^{26}$ RIBEIRO, Orlando; LAUTENSACH, Hermann; DAVEAU, Suzanne (Org.). Geografia de Portugal. Lisboa: Edições João Sá da Costa, 1991. v. 4, p. 1009.
} 


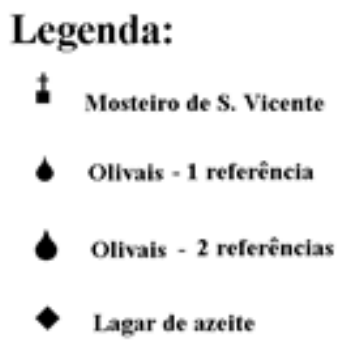

Fonte: Elaborado pelo autor.

\subsubsection{Outras Propriedades}

Por último, surgem na documentação outas propriedades, que não ocupavam, porém, um lugar de destaque, tendo em conta o número de menções encontradas. As hortícolas e leguminosas assumiam uma relevância capital na alimentação do Homem medievo, encontrando-se, no entanto, silenciadas nos documentos do cartório de São Vicente. As ervilhas, o grão de bico, o tremoço e as lentilhas eram algumas dessas espécies, entre outros vegetais e ervas de cheiro, plantados nas almuinhas, com uma dupla finalidade. Por um lado, permitiam um equilíbrio alimentar, onde o pão e o vinho assumiam o lugar principal; por outro, fertilizavam as terras, azotando-as. Estas culturas ocupavam o seu espaço nas quintas e casais, ao lado das vinhas e oliveiras, por vezes, sempre em zonas de fácil e rápido transporte, uma vez que o produto era facilmente deteriorável. A estes bens fundiários somavam-se as quintas e os casais, as salinas e as marinhas, assim como as albergarias.

\section{Conclusão}

A fundação do Mosteiro teve lugar na sequência, como vimos, da conquista da cidade de Lisboa, da qual a canónica é indissociável, bem como da sua organização interna e dos princípios espirituais pelos quais se pautavam os seus membros no cumprimento da Regula Prima. A constituição e a gestão do seu valioso e extenso património fundiário fizeram de São Vicente, pela sua fama e autoridade, o mais prestigiado Mosteiro da península de Lisboa, nos séculos XII e XIII, procurando ombrear com a sua casa-mãe - Santa Cruz de Coimbra - e Santa Maria de Alcobaça, constituindo, com estes dois, os mais destacados mosteiros do Portugal medieval. 
Outros Tempos, vol. 14, n. 23, 2017 p. 240 -259. ISSN:1808-8031

Tendo-se projetado, desde início, física e espiritualmente, sobretudo no termo de Lisboa, situação que caracterizou a aquisição de um património concentrado nesta região, não deixou de estender a sua influência a nível nacional, dados os direitos e privilégios que possuía no reino, bem como a sua ligação ao rei, a alguns membros da família real e às elites urbanas, fazendo de Vicente um santo preferencialmente da urbe. Aquisição de poder, autoridade e prestígio que explicam os litígios da canónica com o clero secular, cujos interesses eram, na maioria das vezes, necessariamente contraditórios.

No Mosteiro, os cónegos regrantes "ofereciam” a salvação da alma, o perdão dos erros cometidos e o descanso eterno, ao mesmo tempo que garantiam, pela oração, o Além. Nos campos, faziam frutificar as colheitas, que abasteceriam igualmente o refeitório, a sacristia e o hospital, no exercício da assistência e da caridade, e em obediência aos princípios da Regula. Procuravam, deste modo, dentro e fora da canónica, diminuir a dureza do mundo terreno, procurando um lugar na cidade de Deus, cuja entrada parecia garantida através dos cuidados físicos e espirituais que dedicavam ao próximo, eternos garantes de um lugar no Céu. 